\title{
Respiratory muscle and pulmonary function in polymyositis and other proximal myopathies
}

\author{
NORMA MT BRAUN, NARINDER S ARORA, DUDLEY F ROCHESTER
}

From the Cardiorespiratory Laboratory, Department of Medicine, College of Physicians and Surgeons, Columbia University, New York; and the Pulmonary-Allergy Division, Department of Internal Medicine, University of Virginia School of Medicine, Charlottesville, Virginia, USA

ABSTRACT We studied 53 patients with proximal myopathy to determine at what level of muscle weakness hypercapnic respiratory failure is likely, and which tests of pulmonary function or respiratory muscle strength would best suggest this development. Respiratory muscle strength was determined from maximal static efforts and in half the patients, both inspiratory and expiratory muscle strengths were less than $50 \%$ of normal. In the 37 patients without lung disease respiratory muscle weakness was accompanied by significant decreases in vital capacity, total lung capacity, and maximum voluntary ventilation; by significant increases in residual volume and arterial carbon dioxide tension $\left(\mathrm{PaCO}_{2}\right)$; and greater likelihood of dependence on ventilators, atelectasis, and pneumonia. Hypercapnia was particularly likely when respiratory muscle strength was less than $30 \%$ of normal in uncomplicated myopathy, and when vital capacity was less than $55 \%$ of the predicted value in any patient.

Myopathies which affect proximal limb muscles may also affect respiratory muscles; ${ }^{1-7}$ but the relationships between the extent to which respiratory muscles are affected, abnormality of pulmonary function, and the onset of respiratory failure have not been defined. We addressed these questions in a group of 53 patients with various proximal myopathies.

\section{Methods}

The patients studied were adults with myopathy from the neurology and medicine services of Harlem Hospital Center and Columbia Presbyterian Medical Center in New York and the University of Virginia Hospital in Charlottesville. They were referred for evaluation of pulmonary or respiratory muscle function or both. They represent about one-third of all patients with a diagnosis of myopathy at these hospitals during the period of the study.

Myopathy was diagnosed by conventional criteria

Address for reprint requests: Dr Norma MT Braun, Cardiorespiratory Laboratory, College of Physicians and Surgeons, Presbyterian Hospital-Stem 7, 630 West 168th Street, New York, NY 10032, USA.

Accepted 20 April 1983 (table 1). Patients with neoplasm, diabetes mellitus, thyroid or parathyroid disease, chronic renal insufficiency, sarcoidosis, and granulomatous lung disease were excluded from the study.

Vital statistics are summarised in table 2. Patients with polymyositis or dermatomyositis (group I) had had symptoms for three months to two years; the symptoms of patients with other myopathies (group II) had lasted from several months to many years. Thirty-seven patients with no evidence of chronic lung disease (groups IA, IIA) were considered separately from the 16 patients with myopathy and

Table 1 Type and frequency of myopathy in the 53 patients studied

\begin{tabular}{|c|c|c|}
\hline Diagnosis & No & $\%$ \\
\hline $\begin{array}{l}\text { Total patients with polymyositis } \\
\text { Polymyositis alone } \\
\text { Polymyositis with dermatomyositis } \\
\text { Polymyositis with mixed connective tissue } \\
\text { disease } \\
\text { Total patients with chronic myopathies } \\
\text { Acid maltase deficiency } \\
\text { Idiopathic myopathy } \\
\text { Alcoholic myopathy } \\
\text { Carnitine deficiency } \\
\text { Glycogen-debrancher enzyme deficiency } \\
\text { Ragged red fibre disease } \\
\text { Lipid storage myopathy } \\
\text { Steroid myopathy }\end{array}$ & $\begin{array}{r}31 \\
26 \\
3 \\
2 \\
22 \\
6 \\
6 \\
4 \\
2 \\
1 \\
1 \\
1 \\
1\end{array}$ & $\begin{array}{r}58 \cdot 5 \\
49 \cdot 1 \\
5 \cdot 7 \\
3 \cdot 8 \\
41 \cdot 5 \\
11 \cdot 3 \\
11 \cdot 3 \\
7 \cdot 5 \\
3 \cdot 7 \\
1 \cdot 9 \\
1 \cdot 9 \\
1 \cdot 9 \\
1 \cdot 9\end{array}$ \\
\hline
\end{tabular}


Table 2 Mean (SD) age and height and sex distribution of the four groups of patients

\begin{tabular}{lllll}
\hline Groups $^{*}$ & $I A$ & $I I A$ & $I B$ & $I I B$ \\
\hline Age(y) & $41(15)$ & $40(13)$ & $54(15)$ & $41(14)$ \\
Height (cm) & $164(8)$ & $174(12)$ & $174(11)$ & $177(6)$ \\
Sex & $5 \mathrm{M}$ & $10 \mathrm{M}$ & $7 \mathrm{M}$ & $6 \mathrm{M}$ \\
& $15 \mathrm{~F}$ & $6 \mathrm{~F}$ & $3 \mathrm{~F}$ & \\
\hline
\end{tabular}

${ }^{*}$ Group I comprises patients with polymyositis or dermatomyositis and group II patients with other proximal myopathies; groups IA and IIA have no chronic lung disease and IB and IIB have interstitial or obstructive lung disease.

chronic obstructive or interstitial lung disease (groups IB, IIB). Criteria for a diagnosis of obstructive lung disease included a history of cigarette smoking, chronic cough and sputum production, and a ratio of $\mathrm{FEV}$, to vital capacity of less than $70 \%$. The diagnosis of interstitial lung disease was made from an interstitial pattern on the chest radiograph; this was present in five patients with polymyositis and one with alcoholic myopathy.

Spirometric volumes were measured by either a 13.5-litre water-filled spirometer with large-bore tubing (Warren E Collins, Braintree, Montana) or an Automated Pulmonary Functional Lab Mark I (System Research Laboratories Inc, Dayton, Ohio). Measurements included slow and forced vital capacity (VC, FVC), FEV and the ratio FEV/FVC. The 12-second maximum voluntary ventilation (MVV) was measured with the water-filled spirometer in $\mathbf{4 0}$ patients. Functional residual capacity (FRC) was determined by helium dilution in 22 patients. Total lung capacity (TLC) was calculated as the sum of FRC and inspiratory capacity. In three additional patients, TLC was calculated using posteroanterior and lateral chest radiographs taken at full inspiration, a modification of the Barnhard ellipse method being used. ${ }^{8}$ Residual volume (RV) was calculated as the difference between TLC and VC. Vital and total lung capacities were expressed as percentage of predicted normal values (VC\%, TLC\%), and RV was expressed as percentage of predicted TLC (RV\%).

Maximum static inspiratory and expiratory pressures at the mouth were measured in 47 patients by the technique of Black and Hyatt. ${ }^{9}$ Maximum inspiratory pressure $\left(\mathrm{Pi}_{\max }\right)$ was measured at $\mathrm{RV}$ and maximum expiratory pressure $\left(\mathrm{Pe}_{\max }\right)$ at TLC. These values were expressed as percentage of the predicted normal ( $\mathrm{Pi} \%$ and $\mathrm{Pe} \%$ ) for persons of the same sex and age group (table 3 ). Respiratory muscle strength (RMS\%) was calculated as the average of $\mathrm{Pi} \%$ and $\mathrm{Pe} \%$. The reported values of spirometric data and respiratory muscle pressures were the best of three efforts.

In the presence of respiratory muscle weakness the measured values of $\mathrm{Pe}_{\max }$ and $\mathrm{Pi}_{\max }$ may be affected by lung volume as well as by myopathy. If inspiratory muscle weakness prevents the patients from achieving a normal TLC, then $\mathrm{Pe}_{\max }$ will be measured at a lung volume where the expiratory muscles are contracting from a resting length less than optimum. With expiratory muscle weakness the maximum inspiratory manoeuvre may be performed at a lung volume where the inspiratory muscles contract from a shorter-than-optimal length, reducing the observed $\mathrm{Pi}_{\text {ip. }}$. To correct for these effects of lung volume on $\mathrm{Pi}_{\text {max }}$ and $\mathrm{Pe}_{\text {max }}$, we used Ringqvist's regression equations predicting $\mathrm{Pi} \%$ and $\mathrm{Pe} \%$ from lung volume expressed as percentage of predicted TLC. ${ }^{10}$

Arterial blood gas composition was determined in 45 patients, each patient having at least two samples taken. In eight patients end-tidal carbon dioxide tension $\left(\mathrm{PCO}_{2}\right)$ was measured with a carbon dioxide analyser (Mark I Capnograph, Godart) to estimate arterial carbon dioxide tension $\left(\mathrm{PaCO}_{2}\right)$. The alveolar-arterial oxygen tension gradient $\left(\mathrm{AaPo}_{2}\right)$ was calculated from the alveolar air equation, a respiratory quotient of 0.8 being assumed.

Statistical analyses included $\chi^{2}$ tests with Yates's correction, $t$ tests for differences between two group means, and linear regression analysis. Data in text and tables are reported as means and standard deviations (SD).

\section{Results}

Normal values for $\mathrm{Pi}_{\max }$ and $\mathrm{Pe}_{\max }$ in men and women aged $14-49$ and $50-70$ years were obtained at the University of Virginia Hospital (table 3) and are similar to those reported elsewhere. ${ }^{9}{ }^{10}$ The largest coefficient of variation in table 3 is $30 \%$, so that any value of $\mathrm{Pi}_{\text {max }}$ or $\mathrm{Pe}_{\text {max }}$ lower than $70 \%$ of the mean is more than one standard deviation below the mean normal value.

In the 47 subjects in whom measurements of maximum pressures were made $\mathrm{Pi}_{\text {max }}$ averaged 48 (19) $\mathrm{cm} \mathrm{H}_{2} \mathrm{O}$ and $\mathrm{Pe}_{\max } 80$ (41) $\mathrm{cm} \mathrm{H}_{2} \mathrm{O}$, both significantly below normal $(p<0.001)$. Overall respiratory muscle strength (RMS) was less than $70 \%$ of normal (moderate weakness) in 37 patients and less than $50 \%$ of normal (severe weakness) in 24 of the 47 patients. The prevalence of moderate and severe respiratory muscle weakness was not significantly different in patients with polymyositis or dermatomyositis (group I) from that in patients with congenital and miscellaneous myopathies (group II). The ratio $\mathrm{Pi}_{\text {max }} / \mathrm{Pe}$ averaged $0.57(0.20)$, which is not significantly different from the normal values of $0.58(0.12)$ for men and $0.65(0.14)$ for women (table $3)$. This indicates that loss of strength was distributed evenly among inspiratory and expiratory muscles. 
Table 3 Normal mean (SD) values of maximum static inspiratory and expiratory pressures measured at the mouth $\left(P_{i_{\text {max }}}\right.$ $P e_{\text {max }}$ ) and the ratio $P i_{\text {max }}\left(P e_{\text {max }}\right.$ (coefficient of variation (\%) in square brackets)

\begin{tabular}{|c|c|c|c|c|}
\hline & Males & & Females & \\
\hline Age (y) & $14-49$ & $50-70$ & $14-49$ & $50-70$ \\
\hline Number & 80 & 27 & 121 & 28 \\
\hline $\mathrm{Pi}_{\max }\left(\mathrm{cm} \mathrm{H} \mathrm{H}_{2} \mathrm{O}\right)$ & $127(28)[22]$ & $122(20)[18]$ & $91(25)[27]$ & $77(18)[23]$ \\
\hline $\mathrm{Pe}_{\max }\left(\mathrm{cm} \mathrm{H}_{2} \mathrm{O}\right)$ & $216(45)[21]$ & $196(45)[23]$ & $138(39)[28]$ & $124(37)[30]$ \\
\hline $\mathrm{Pi}_{\max } / \mathrm{Pe}_{\max }$ & $0.59(0 \cdot 12)$ & $0.58(0 \cdot 12)$ & $0 \cdot 67(0 \cdot 16)$ & $0.65(0 \cdot 14)$ \\
\hline
\end{tabular}

When $\mathrm{Pi} \%$ and $\mathrm{Pe} \%$ were plotted against each other the regression line was not significantly different from the line of identity (fig 1 ).

Total lung capacity (TLC) and residual volume (RV) were measured in 22 of the patients whose $\mathrm{Pi}_{\max }$ and $\mathrm{Pe}_{\max }$ were measured. The mean corrections for the effect of lung volume and $\mathrm{Pi}_{\max }$ and $\mathrm{Pe}_{\text {mex }}$ were $9 \%(3 \%)$ and $12 \%(4 \%)$ of the observed value respectively. As a result, for this subset of

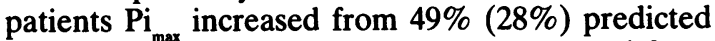
to $54 \%(32 \%)$ predicted, and $\mathrm{Pe}_{\max }$ increased from $45 \%(22 \%)$ to $51 \%(25 \%)$ predicted. The distribution of weakness between inspiratory and expiratory muscles was not significantly affected by the lung volume corrections.

The mean values for respiratory muscle strength, pulmonary function results, and arterial blood gas composition in each of the groups are given in table 4. All patients with myopathy uncomplicated by chronic lung disease (groups IA and IIA) had normal values of $\mathrm{FEV}, \mathrm{VC}$, and there were significant

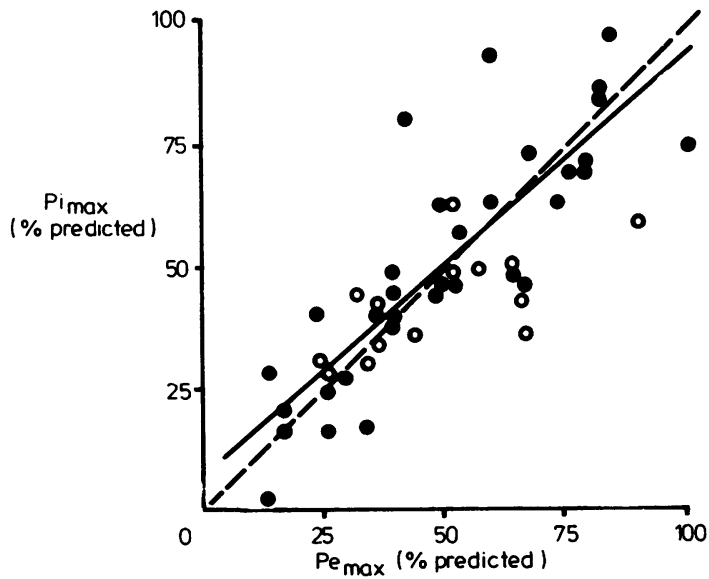

Fig 1 Relationship between maximum static inspiratory and expiratory pressures ( $\mathrm{Pi}, \mathrm{Pe})$ in 33 patients with myopathy uncomplicated by chronic lung disease (closed circles, regression line) and 14 with myopathy plus chronic interstitial or obstructive lung disease (open circles). The solid regression line $(r=0.841, p<0.001)$ is not significantly different from the dashed line of identity. reductions from normal in $\mathrm{Pi} \%, \mathrm{Pe} \%, \mathrm{RMS} \%$, TLC\%, VC\%, and MVV\%; AaPo, was greater than normal. The reductions in $\mathrm{Pi} \%, \mathrm{Pe} \%$, RMS\%, and MVV\% were greater in group IIA, which includes patients with congenital myopathies, than in group IA (patients with polymositis or dermatomyositis) ( $\mathrm{p}$ $<0.05)$.

To assess the effect of coexistent chronic lung disease we compared groups IA and IIA with groups IB and IIB. The patients with chronic lung disease (groups IB, IIB) had significantly lower values of MVV\% and arterial oxygen tension $\left(\mathrm{PaO}_{2}\right)$ and higher values of $\mathrm{AaPo}$ than did the patients without chronic lung disease (groups IA, IIA) $(p<0.05)$. There were no significant differences between those with and without chronic lung disease with respect to $\mathrm{Pi} \%, \mathrm{Pe} \%$, RMS\%, VC\%, or $\mathrm{PaCO}_{2}$.

Six of the patients with myopathy had interstitial lung disease; their $\mathrm{FEV}_{1} / \mathrm{VC}$ averaged $84 \%$ (5\%), not significantly different from the values in patients without chronic lung disease. As expected, the 10 patients with obstructive lung disease had an FEV/ VC averaging 54\% (15\%). Otherwise, there were no differences between patients with interstitial and obstructive disease with respect to $\mathrm{Pi} \%, \mathrm{Pe} \%$, RMS\%, TLC\%, MVV\%, arterial blood gas composition, or $\mathrm{AaPo}_{2}$.

To illustrate the relationships between respiratory muscle weakness, pulmonary function, and gas exchange, we plotted several ventilatory and blood gas variables as functions of respiratory muscle strength (figs 2-5). In these figures regression lines in the figures represent data from groups IA and IIA only.

Residual volume (RV\%) was inversely related to $\mathrm{Pe} \%$ (fig 2). The values from groups IB and IIB were within the $95 \%$ confidence limits of the regression based on groups IA and IIA. There were no correlations between $\mathrm{TLC} \%$ and $\mathrm{Pe} \%, \mathrm{Pi} \%$, or RMS\%.

Vital capacity (VC\%) showed a significant linear correlation with RMS\%: VC\% $=0.523$ RMS\% $\pm \frac{\text { Pे }}{\mathbb{D}}$ $38.3(\mathrm{~N}=33, \mathrm{r}=0.642, \mathrm{p}<0.001)$, but the relationship appears curvilinear. Hence we used a $\stackrel{\square}{\square}$ $\log -\log$ relationship and found that the correlation 
Table 4 Mean (SD) maximum respiratory pressures, lung volumes, ventilatory capacity, and arterial blood gas values in the four groups of patients (number of observations for each test in square brackets)

\begin{tabular}{lllll}
\hline Group & $I A$ & $I I A$ & $I B$ & $I I B$ \\
\hline $\mathrm{Pi}_{\max }$ (\% predicted) & $60(22)[18]$ & $40(24)[15]$ & $44(12)[8]$ & $39(9)[6]$ \\
$\mathrm{Pe}_{\max }$ (\% predicted) & $57(24)[18]$ & $42(21)[15]$ & $51(21)[8]$ & $46(18)[6]$ \\
$\mathrm{RMS}$ (\% predicted) & $58(21)[18]$ & $41(22)[15]$ & $48(15)[8]$ & $43(12)[6]$ \\
TLC (\% predicted) & $69(8)[10]$ & $66(9)[5]$ & $66(7)[6]$ & $74(3)[2]$ \\
$\mathrm{RV}$ (\% predicted TLC) & $29(11)[10]$ & $39(12)[5]$ & $30(7)[6]$ & $27(4)[2]$ \\
VC (\% predicted) & $62(19)[21]$ & $62(25)[16]$ & $56(12)[10]$ & $63(21)[6]$ \\
FEV $/ \mathrm{VC}(\%)$ & $85(5)[19]$ & $88(7)[16]$ & $70(19)[10]$ & $58(17)[6]$ \\
$\mathrm{MVV}$ (\% predicted) & $69(14)[13]$ & $54(23)[14]$ & $45(23)[9]$ & $35(7)[4]$ \\
$\mathrm{PaCO}_{2}$ (mmHg) & $40(8)[21]$ & $44(9)[16]$ & $43(9)[10]$ & $42(9)[6]$ \\
$\mathrm{PaO}_{2}$ (mmHg) & $77(14)[15]$ & $79(13)[14]$ & $65(13)[9]$ & $73(9)[5]$ \\
$\mathrm{AaPo}_{2}$ (mmHg) & $22(9)[15]$ & $16(11)[14]$ & $31(17)[9]$ & $23(10)[5]$ \\
\hline
\end{tabular}

*See footnote to table 2 for definition of groups.

$\mathrm{Pi}_{\text {ix }}, \mathrm{Pe}_{\text {max }}$-maximum static inspiratory and expiratory pressure; RMS - respiratory muscle strength; TLC-total lung capacity; RVresidual volume; VC-vital capacity; $\mathrm{FEV}_{1}$-one-second forced expiratory volume; $\mathrm{MVV}_{1}$-maximum voluntary ventilation; $\mathrm{Paco}_{2}, \mathrm{PaO}_{2}-$ arterial carbon dioxide and oxygen tensions; $\mathrm{AaPo}_{2}$-alveolar-arterial oxygen tension gradient.

Conversion: Traditional to SI units-Blood gases: $1 \mathrm{mmHg} \approx 0.133 \mathrm{kPa}$.

coefficient and the explained variance in VC\% were higher (fig 3). Only three patients from groups IB and IIB had values of VC\% which lay below the $95 \%$ confidence limits of the regression.

Maximum voluntary ventilation (MVV\%) was linearly related to RMS\% (fig 4). Six patients from groups IB and IIB had values of MVV\% which lay below the $95 \%$ confidence limits of the regression calculated from group IA and IIA data.

The group mean values (table 4) obscure any relationship between carbon dioxide retention and respiratory muscle weakness. When data from the 33 patients without lung disease were plotted, however,

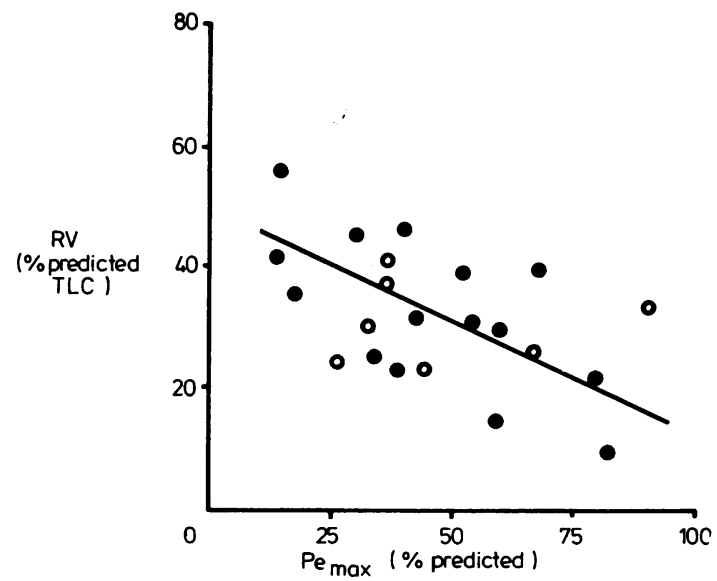

Fig 2 Relationship between residual volume $(R V)$ and expiratory pressure $\left(\mathrm{Pe}_{\mathrm{ax}}\right)$ in 15 patients with uncomplicated myopathy (closed circles, regression line) and seven with myopathy plus chronic lung disease (open circles). The equation of the line is: $R V \%=48.9-0.361$ $\mathrm{Pe} \%(r=-0.651, p<0.01)$.
$\mathrm{Paco}_{2}$ appeared to be a discontinuous function of RMS\% (fig 5). Below an RMS value of $50 \%$ predicted $\mathrm{PaCO}_{2}$ increased linearly as RMS fell ( $\mathrm{p}<$ 0.01 ). When RMS exceeded $50 \%$ of the predicted value $\mathrm{PaCO}_{2}$ was normal and independent of RMS\%. Five of the 14 patients in groups IB and IIB had $\mathrm{PacO}_{2}$ values that exceeded the $95 \%$ confidence limits of the regressions calculated from groups IA and IIA data. The results were virtually identical when $\mathrm{Pi}_{\max }$ and Pi\% were substituted for RMS\%.

In contrast to the relationship between $\mathrm{PaCO}_{2}$ and RMS\%, the relationship between $\mathrm{PaCO}_{2}$ and VC\% appeared to be linear throughout the range of $\mathrm{VC} \%$

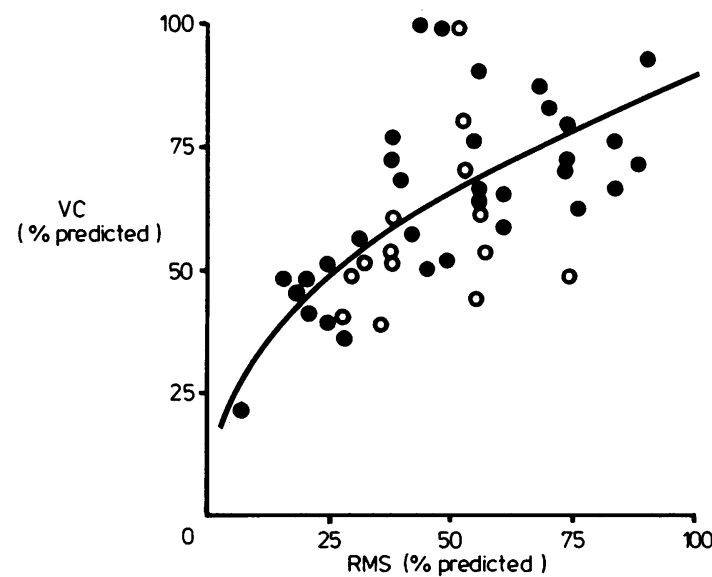

Fig 3 Relationship between vital capacity (VC) and respiratory muscle strength (RMS) in 33 patients with uncomplicated myopathy (closed circles, regression line) and 17 with myopathy plus chronic lung disease (open circles). The equation of the line is: $\log V C \%=1.051+$ $0.499 \log R M S \%$ (SEE 0.089, $r=0.794, p<0.001$ ). 


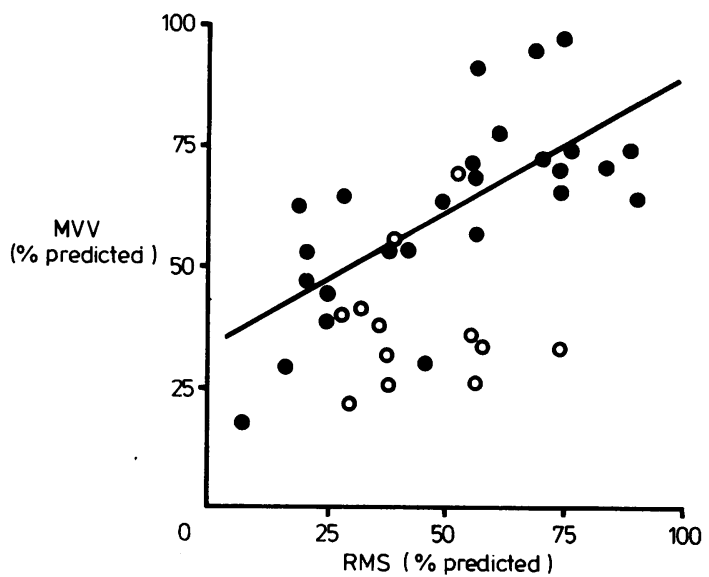

Fig 4 Relationship between maximum voluntary ventilation (MVV) and respiratory muscle strength (RMS) in 26 patients with uncomplicated myopathy (closed circles, regression line) and 12 with myopathy plus chronic lung disease (open circles). The equation of the line is: MVV\% $=33.2+0.574$ RMS\% $(r=0.708, p<0.001)$.

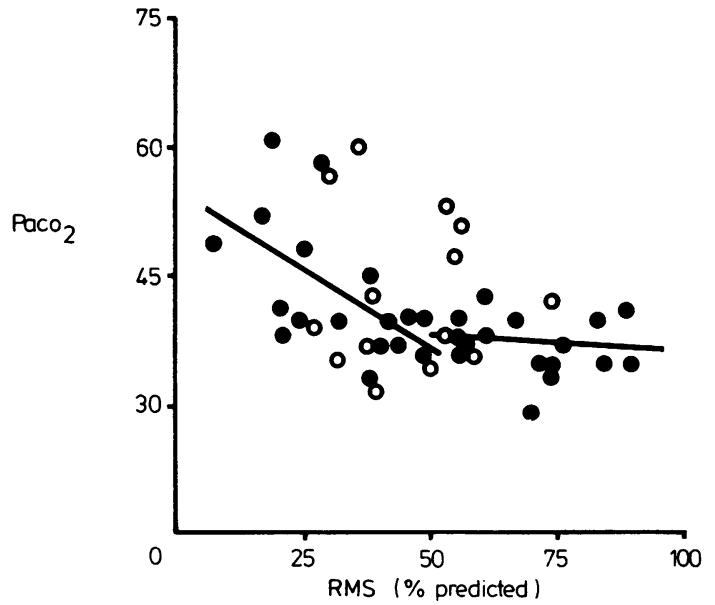

Fig 5 Relationship between arterial carbon dioxide tension $\left(\mathrm{PaCO}_{2}\right)(\mathrm{mm} \mathrm{Hg})$ and respiratory muscle strength (RMS) (\%) in 33 patients with uncomplicated myopathy (closed circles, regression line) and 14 patients with myopathy plus chronic lung disease (open circles). The equation of the line when $R M S<50 \%$ predicted is: $P a c o=55-0.37 R M S(r$ $=-0.587, p<0.02)$. When $R M S>50 \%$ predicted the equation is: $\mathrm{PaCO}_{2}=40-0.045 \mathrm{RMS}(\mathrm{NS})$. Conversion: Traditional to SI units-Paco, $1 \mathrm{~mm} \mathrm{Hg} \approx 0.133 \mathrm{kPa}$.

in patients from groups IA and IIA (fig 6). The plot includes three patients with carbon dioxide retention and low values of VC in whom RMS was not measured. The data points from groups IB and IIB patients lay within the $95 \%$ confidence limits of the

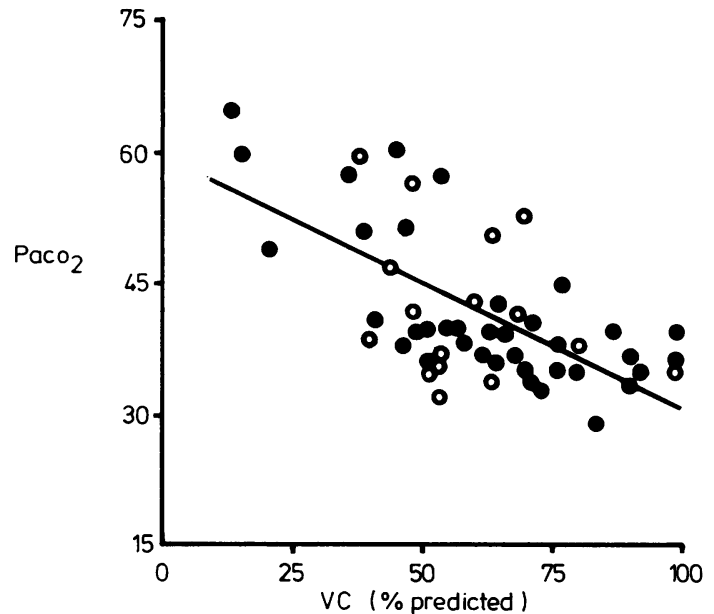

Fig 6 Relationship between arterial carbon dioxide tension $\left(\mathrm{PaCO}_{2}\right)(\mathrm{mm} \mathrm{Hg})$ and vital capacity $(\mathrm{VC})$ in 37 patients with uncomplicated myopathy (closed circles, regression line) and 16 with myopathy plus chronic lung disease (open circles). The equation of the line is: $\mathrm{PaCO}_{2}=59.7-0.288$ $V C \%(r=-0.711, p<0.001)$.

regression calculated from the groups IA and IIA data.

Serious complications potentially attributable to respiratory, laryngeal, or pharyngeal muscle weakness occurred in 20 of the 53 patients with myopathy. There were five deaths; seven patients remain dependent on ventilators; and 10 have had recurrent aspiration pneumonia and atelectasis (one of the pneumonia group was also ventilator dependent). For the entire group there was no relationship between muscle weakness and the development of complications. In groups IA and IIA, however, nine of the $17(53 \%)$ with RMS less than $50 \%$ of predicted had complications, but only one of the 16 patients (6\%) whose RMS exceeded $50 \%$ of predicted (p < $0.02)$. In two patients with polymyositis the severity of the respiratory muscle weakness was not initially appreciated, and respiratory muscle strength was not measured. One of these died of acute and the other of chronic hypercapnic respiratory failure.

\section{Discussion}

The clinical and physiological expressions of myopathy in these patients were similar to those in patients described by others. ${ }^{1-7}$ 11-16 $^{16}$ No previous study, however, has related the development of hypercapnia to the degree of respiratory muscle dysfunction. Congenital myopathies and polymyositis are well known to affect the respiratory muscles, and corticosteroid treatment has been implicated as a 
cause of respiratory muscle weakness in obese asthmatic patients. ${ }^{17} \mathrm{We}$ also found respiratory muscle weakness in alcoholic myopathy (table 1).

Since lung disease might be expected to affect adversely the respiratory muscles, we included 16 patients with chronic pulmonary disease; our patients with polymyositis and interstitial lung disease had values of total lung capacity, vital capacity, and $\mathrm{PaCO}_{2}$ that were virtually identical to those reported by Salmeron et al. ${ }^{18}$ Ten others had chronic obstructive lung disease not related to the myopathy. The functional abnormalities were greater in the patients with additional obstructive or interstitial lung disease; the influence of lung disease was, however, small and this may have been related to the fact that airflow obstruction was mild or only moderately severe in the patients studied.

Thirty-eight percent of our patients had complications attributable to muscle weakness, including carbon dioxide retention and ventilator dependence; there were five deaths. These complications were significantly related to respiratory muscle weakness.

We found that the deficit in respiratory muscle strength was evenly distributed between inspiratory and expiratory muscles in patients with myopathy (fig 1). This conclusion was not altered when $\mathrm{Pi}$ and $\mathrm{Pe}_{\max }$ were corrected for lung volume, as has also been shown for the distribution of muscle weakness in undernourished patients. ${ }^{19}$ In contrast, patients with amyotrophic lateral sclerosis, Duchenne's dystrophy, myotonic dystrophy, ${ }^{20}{ }^{21}$ myasthenia gravis, ${ }^{22}$ and curarised normal volunteers ${ }^{23}$ have more weakness of the expiratory muscles than of the inspiratory muscles. The reason for the even distribution of weakness in myopathy and undernutrition and the predominance of expiratory muscle weakness in the other diseases is not known.

The increase in residual volume with progressive expiratory muscle weakness (fig 2) resulted from inability of weakened expiratory muscles to force thoracic volume below functional residual capacity (FRC), which is the resting volume of the respiratory system. Kreitzer et a ${ }^{20}$ found a similar relationship between residual volume and expiratory muscle weakness with amyotrophic lateral sclerosis.

Both total lung capacity and vital capacity are determined by the balance between respiratory system recoil and the force generated by contraction of the respiratory muscles. Above FRC most of the respiratory system recoil is contributed by the lungs. ${ }^{24}$ Respiratory system recoil could be altered because of changes in lung or chest wall compliance. A reduction in lung compliance has been found ${ }^{11}{ }^{12}$ but its mechanism is not entirely clear. One reason may be that alterations in the configuration of surfactant and microatelectasis attend low tidal volumes. ${ }^{11}{ }^{12}$ The increase in $\mathrm{AaPo}_{2}$ in our patients of groups IA and IIA (table 4) is consistent with this hypothesis. A further reason may be that inspiratory muscle weakness results in the inability to develop a large inflation volume history, which reduces the slope of the pulmonary volume-pressure curve. ${ }^{25}$ Thus we would expect that the weaker the inspiratory muscles the lower would be TLC and VC. In fact, for TLC no such relation was observed. Others have found TLC to be normal ${ }^{20}$ or reduced ${ }^{71}$ in patients with muscle weakness of various causes.

The relationship between vital capacity and respiratory muscle strength is curvilinear. ${ }^{12} 26$ Because the static recoil curve is sigmoid, reducing respiratory strength to $50 \%$ of normal would theoretically reduce VC by only about $15 \%$, whereas further muscle weakness should produce a greater reduction in VC. Our results (fig 3) generally agree with those of others $^{1228}$ in that VC was lower than predicted from theoretical considerations. ${ }^{1226}$ The discrepancy between the theoretical and observed behaviour of the vital capacity as a function of respiratory muscle strength could be explained by alterations either in the force-length relation of the weakened muscles or in the static recoil curve of the respiratory system. To our knowledge, the force-length curve of myopathic muscles has not been characterised. In curarised normal volunteers, however, transdiaphragmatic pressure during maximum static inspiratory efforts was reduced proportionately at all lung volumes. ${ }^{23} 29$ This suggests that, while force at any given diaphragm muscle length was reduced, the intrinsic shape of the force-length curve was preserved. Thus the disproportionate reduction of vital capacity in neuromuscular disease is probably not explained by abnormal muscle mechanics alone.

The magnitude of the maximum voluntary ventilation has been shown to be a function of respiratory muscle strength in normal subjects, ${ }^{30}$ undernourished patients, ${ }^{19}$ patients with obstructive and interstitial lung diseases ${ }^{31}$ and patients with other neuromuscular diseases, ${ }^{71}$ and now in patients with myopathy (fig 4). In contrast to the relationships between $R V$ or VC and RMS, the MVV-RMS relation was relatively sensitive to the presence of coexistent lung disease (fig 4). The dependence of MVV on respiratory muscle strength is attributable to the relationship between pressure and airflow. In maximum inspiratory efforts airflow depends on pressure throughout inspiration, but in maximal expiratory efforts airflow is pressure dependent only in early expiration. ${ }^{732}$ During maximum voluntary ventilation both inspiratory and expiratory muscle pressures contribute to airflow and minute volume. Because the effort is sustained for only 12-15 seconds, the strength of the respiratory muscles, rather than their endurance 
characteristics, appears to be of paramount importance in determining MVV.

Respiratory failure with carbon dioxide retention is a serious complication of generalised myopathy. Nine of our patients without lung disease had hypercapnia; this was clearly related to respiratory muscle weakness in six (fig 5), and undoubtedly attributable to respiratory muscle weakness in two of the other three, whose VC was less than $20 \%$ of predicted. There was a discontinuous relationship between $\mathrm{PaCO}_{2}$ and respiratory muscle strength (fig 5), such that hypercapnia did not appear until RMS was less than $40 \%$ of normal, and it was not severe until RMS had dropped to $30 \%$ of normal.

The vital capacity has long been used to reflect the severity of respiratory muscle weakness and to predict respiratory failure in neuromuscular diseases $^{32-36}$ and an inverse relationship between arterial carbon dioxide tension and vital capacity has been noted in previous studies. ${ }^{2}{ }^{3}{ }^{11}{ }^{13} \mathrm{We}$ found a similar relationship (fig 6) but severe hypercapnia was present in some patients with VC as high as $55 \%$ of predicted. The difference in the shape of the $\mathrm{PaCO}_{2}-\mathrm{RMS}$ and $\mathrm{PaCO}_{2}-\mathrm{VC}$ relationships reflects the curvilinear nature of the VC-RMS relationship (fig 3), but the advantage of relating $\mathrm{PaCO}_{2}$ to RMS instead of to VC is that the $\mathrm{PaCO}_{2}-\mathrm{RMS}$ graph more readily identifies the patients in whom respiratory muscle weakness is the primary cause of hypercapnia (fig 5).

In several reported cases of neuromuscular disease hypercapnia appears to have resulted primarily from reduced ventilatory drive,,$^{13}{ }^{14}{ }^{37}$ even when respiratory muscle weakness was minimal. ${ }^{14}$ Ventilatory drive, however, is usually well preserved in neuromuscular disease, as judged from normal mouth occlusion pressures despite substantial respiratory muscles weakness. ${ }^{38-40}$ We have found the same to be true in four of our patients with acid maltase deficiency, two of whom had RMS values of $7 \%$ and $14 \%$ of predicted, and $\mathrm{PaCO}_{2}$ of 61 and $49 \mathrm{~mm} \mathrm{Hg}(8 \cdot 1$ and $6.5 \mathrm{kPa}$.

We conclude that respiratory muscle weakness alone is sufficient to account for hypercapnia when respiratory muscle strength is less than $30 \%$ of normal. Vital capacity is a useful index, and a reduction below $55 \%$ of predicted in patients with neuromuscular diseases is likely to be associated with hypercapnia. If, however, carbon dioxide retention is found with a VC above this level or with RMS greater than $30 \%$ normal, coexistent lung disease or abnormality of ventilatory control, or both, are probably also contributory.

This work was supported by National Institutes of Health grants HL 00371 (pulmonary academic award) and HL 22022. We thank attending physicians of the neurology services at Harlem, Presbyterian, and University of Virginia Hospitals for referring patients for study; Dr Grace Young, Nordel McWhethy, and Barbara Brent for technical assistance; and Linda Dillenhunt, Betty Edmondson, and Cynthia Foster for their help in preparing the manuscript.

\section{References}

${ }^{1}$ Engel AG. Acid maltase deficiency in adults: studies in four cases of a syndrome which may mimic muscular dystrophy or other myopathies. Brain 1970;93:599 616.

${ }^{2}$ Rosenow EC III, Engel AG. Acid maltase deficiency in adults presenting as respiratory failure. $\mathrm{Am} \mathrm{J} \mathrm{Med}$ 1978;64:485-91.

${ }^{3}$ Lightman NI, Schooley RT. Adult onset acid maltase deficiency: case report of an adult with severe respiratory difficulty. Chest 1977;72:250-2.

${ }^{4}$ DiMauro S, Stern LZ, Mehler M, Nagle RB, Payne C. Adult-onset acid maltase deficiency: a postmortem study. Muscle Nerve 1978;1:27-36.

${ }^{5}$ Engel AG, Angeline C, Nelson RA. Identification of carnitine deficiency as a cause of human lipid storage myopathy. In: Milhorat AT, ed. Exploratory concepts in muscle II. Control mechanisms in development and function of muscle and their relationship to muscular dystrophy. Amsterdam: International Congress Series, Excerpta Medica, 1975:601-17.

${ }^{6}$ Hepper NGG, Ferguson RH, Howard FM jun. Three types of pulmonary involvement in polymyositis. Med Clin North Am 1964;48:1031-41.

${ }^{7}$ Black LF, Hyatt RE. Maximal static respiratory pressures in generalized neuromuscular disease. Am Rev Respir Dis 1971;103:641-50.

${ }^{8}$ Reger RB, Young A, Morgan WKC. An accurate and rapid radiographic method of determining total lung capacity. Thorax 1972;27:163-8.

${ }^{9}$ Black LF, Hyatt RE. Maximal respiratory pressures: normal values and relationship to age and sex. Am Rev Respir Dis 1969;99:686-702.

${ }^{10}$ Ringqvist $T$. The ventilatory capacity in healthy subjects: an analysis of causal factors with special reference to the respiratory forces. Scand J Clin Lab Invest 1966;18,Suppl 88:1-179.

${ }^{11}$ Gibson GJ, Pride NB, Davis JN, Loh LC. Pulmonary mechanics in patients with respiratory muscle weakness. Am Rev Respir Dis 1977;115:389-95.

${ }^{12}$ De Troyer A, Borenstein S, Cordier R. Analysis of lung volume restrictions in patients with respiratory muscle weakness. Thorax 1980;35:603-10.

${ }^{13}$ Bellamy D, Davis JMN, Hickey BP, Benatar SR, Clark TJH. A case of primary alveolar hypoventilation associated with mild proximal myopathy. Am Rev Respir Dis 1975;112:867-73.

${ }^{14}$ Riley DJ, Santiago TV, Daniele RP, Schall B, Edelman NH. Blunted respiratory drive in congenital myopathy. Am J Med 1973;63:459-66.

${ }^{15}$ Davis JN, Goldman M, Loh L, Casson M. Diaphragm function and alveolar hypoventilation. $Q J$ Med (New Series) 1976;45:87-100.

${ }^{16}$ Davis JN, Loh L. Alveolar hypoventilation and respiratory muscle weakness. Bull Eur Physiopathol Respir 
1979;15:45-51.

${ }^{17}$ Melzer E, Sourhada JF. Decrease of respiratory muscle strength and static lung volumes in obese asthmatics. Am Rev Respir Dis 1980;121:17-22.

${ }^{18}$ Salmeron G, Greenberg D, Lidsky MD. Polymyositis and diffuse interstitial lung disease. A review of the pulmonary histopathologic findings. Arch Intern Med 1981;141:1005-10.

${ }^{19}$ Arora NS, Rochester DF. Respiratory muscle strength and maximum voluntary ventilation in undernourished patients. Am Rev Respir Dis 1982;126:5-8.

${ }^{20}$ Kreitzer SM, Saunders NA, Tyler HR, Ingram RH jun. Respiratory muscle function in amyotrophic lateral sclerosis. Am Rev Respir Dis 1978;117:437-47.

${ }^{21}$ Griggs RC, Donohoe KM, Utell MJ, Goldblatt D, Moxley RT. III. Evaluation of pulmonary function in neuromuscular disease. Arch Neurol 1981;38:9-12.

${ }^{22}$ Ringqvist I, Ringqvist T. Respiratory mechanics in untreated myasthenia gravis with special reference to the respiratory forces. Acta Med Scand 1971;190:499 508.

${ }^{23} \mathrm{Gal}$ TJ, Arora NS. Respiratory mechanics in supine subjects during progressive partial curarisation. J Appl Physiol 1982;52:57-63.

${ }^{24}$ Agostoni E, Mead J. Statics of the respiratory system. In: Fenn WO, Rahn H, eds. Handbook of Physiology, Section 3: Respiration, Vol 1. Washington DC: American Physiological Society, 1964:387-409.

${ }^{25}$ De Troyer A, Borenstein S. Acute changes in respiratory mechanics after pyridostigmine injection in patients with myasthenia gravis. Am Rev Respir Dis 1980;121:629-38.

${ }^{26}$ Braun NMT, Rochester DF. Muscular weakness and respiratory failure. Am Rev Respir Dis 1979;119(2):123-5.

${ }^{27}$ Gal TJ, Goldberg SK. Relationship between respiratory muscle strength and vital capacity during partial curarisation in awake subjects. Anesthesiology 1981;54:141-7.

${ }^{28}$ Saunders NA, Rigg JRA, Pengelly LD, Campbell EJM. Effect of curare on maximum static PV relationships of the respiratory system. J Appl Physiol 1978;44:589-95.

${ }^{29} \mathrm{Gal}$ TJ, Goldberg SK. Diaphragmatic function in healthy subjects during partial curarisation. J Appl Physiol 1980;48:921-6.

${ }^{30}$ Lavietes MH, Clifford E, Silverstein D, Stier F, Reichman LB. Relationship of static respiratory muscle pressure and maximum voluntary ventilation in normal subjects. Respiration 1979;38:121-6.

${ }^{31}$ Aldrich TK, Arora NS, Rochester DF. The influence of airway obstruction and respiratory muscle strength on maximal voluntary ventilation in lung disease. Am Rev Respir Dis 1982;126:195-9.

${ }^{32}$ Hyatt RE, Flath RE. Relationship of airflow to pressure during maximal respiratory effort in man. J Appl Physiol 1966;21:477-82.

${ }^{33}$ Lukas DS, Plum F. Pulmonary function in patients convalescing from acute poliomyelitis with respiratory paralysis. Am J Med 1952;12:388-96.

${ }^{34}$ Feltman JA, Newman W, Schwartz A, Stone DJ, Lovelock FJ. Cardiac failure secondary to ineffective bellows action of the chest cage. J Clin Invest 1952;31:762-9.

${ }^{35}$ Ferris BG jun, Warren A, Beals CA. The vital capacity as a measure of the spontaneous breathing ability in poliomyelitis. $N$ Engl J Med 1955;252:618-21.

${ }^{36}$ Kilburn KH, Eagan JT, Sieker HO, Heyman A. Cardiopulmonary insufficiency in myotonic and progressive muscular dystrophy. $N$ Engl J Med 1959;261:1089-96.

${ }^{37}$ Carroll JE, Zwillich CW, Weil JV. Ventilatory response in myotonic dystrophy. Neurology 1977;27:1125-8.

${ }^{38}$ Skatrud J, Iber C, McHugh W, Rasmussen H, Nicholas D. Determinants of hypoventilation during wakefulness and sleep during diaphragmatic paralysis. Am Rev Respir Dis 1980;121:587-93.

${ }^{39}$ Bégin R, Bureau MA, Lupien L, Lemieux B. Control and modulation of respiration in Steinert's myotonic dystrophy. Am Rev Respir Dis 1980;121:281-9.

${ }^{40}$ Bégin R, Bureau MA, Lupien L, Lemieux B. Control of breathing in Duchenne's muscular dystrophy. Am J Med 1980;69:227-34. 